\title{
A REVIEW ON NATURAL FIBERS: EXTRACTION PROCESS AND PROPERTIES OF GRASS FIBERS
}

\author{
IP Lokantara \\ Doctoral Study Program, Faculty of Engineering, Udayana University, \\ Denpasar, Bali, Indonesia \\ Mechanical Engineering Department, Faculty of Engineering, Udayana University, \\ Denpasar, Bali, Indonesia \\ NPG Suardana, IW Surata, INS Winaya \\ Mechanical Engineering Department, Faculty of Engineering, Udayana University, \\ Denpasar, Bali, Indonesia
}

\begin{abstract}
Today, research on natural fibers as composite reinforcement aims to study the extraction process, physical properties, chemical properties and mechanical properties of natural fiber. Natural fiber attracts researchers because it has high specific strength, light density, low cost, good mechanical properties, nonabrasive, environmentally friendly and biodegradable in nature. A brief review has been carried out for using abundant natural fibers available in Indonesia. This paper present a review of Mendong grass, Snake grass, Kusha grass, Arundo donax L, Sansevieria ehrenbergii, Sansevieria cylindrica, Elephant grass, Napier grass, Sansevieria trifasciata, Broom grass, Sisal, Corn husks, and Belulang grass.
\end{abstract}

Keywords: grass fiber, extraction process, chemical properties, physical properties, mechanical properties.

Cite this Article: IP Lokantara, NPG Suardana, IW Surata, INS Winaya, A Review on Natural Fibers: Extraction Process and Properties of Grass Fibers. International Journal of Mechanical Engineering and Technology 11(1), 2020, pp. 84-91. https://iaeme.com/Home/issue/IJMET?Volume=11\&Issue $=1$

\section{INTRODUCTION}

In the last ten years, the use of natural fiber-reinforced composites in the engineering field has increased due to abundant availability, low processing costs, lightweight, good mechanical properties, nonabrasive, eco-environment friendly, easy to decompose in nature [1]. Natural fibers are widely used as composite reinforcement in the marine fields, the automotive, handicraft and household appliances [2,3]. Synthetic fibers such as fiberglass, aramid, and nylon have been used as composite reinforcements for more than fifteen years. This synthetic fiber has many disadvantages, especially from environmental aspects such as long-time 
decomposed in nature, expensive, causes irritation and is toxic when burned [4]. Many researchers have conducted research on natural fibers as an alternative to synthetic fibers by improving the physical and mechanical properties of composite materials [5]. Natural fibers generally extracted from bark, stem, fruit, leaf, and roots of the plant [6-9]. The chemical structure of natural fiber cellulose depends on the origin, age parts (roots, fruits, stems, bark, leaves) taken from plants. The cellulose element in the fiber is covered by several noncellulose elements such as hemicellulose, lignin, wax. Some type of natural fiber such as mendong grass [10], Napier grass [11,12], Elephant grass [13], Snake grass [14], Sansevieria ehrenbergii [15], Wild cane grass [16], Broom grass [17], Kusha grass [18], Sisal [19,20], Sansevieria cylindrica [21], Arundo donax L. [22], Sansevieria trifasciata [23], Corn husk [24] has been investigated as an reinforcement in polymer composite. However, research on new natural fibers still needs to be continued to be investigated to increase alternative fiberglass substitutes as reinforcing polymer composites. Indonesia as one of the tropical countries has diverse plants that have the potential to produce natural fibers, one of which is from the type of grass plants, namely belulang grass (Eleusine indica). In this paper, we will describe the extraction process, physical properties, chemical properties and mechanical properties of various types of grass including belulang grass.

\section{EXTRACTION PROCESS OF GRASS FIBERS}

The fiber extraction process is the process of separating fibers from plant parts (stems, fruits, leaves, bark, and roots). In general, the extraction process that is often used is the mechanical extraction process and the retting process. After extraction of fibers by any of these methods, all extracted fibers are washed away before drying. Proper drying is important as the moisture content in fiber affects fiber quality. Artificial drying results in higher-grade fiber than sun drying. The fibers were dried under a shade to avoid beaching by direct sunlight. Dry fibers and then combed, sorted into different grades and packed into bales. The mechanical extraction process is carried out mechanically using human or machine power. The part of the plant to be separated by fibers is inserted into a corticator machine consisting of two grinding gears that are driven by human or machine power. The gears will grind the plant parts to obtain fiber. The resulting fiber is still dirty, needs to be rinsed with clean water [19]. The water retting process is done by soaking the stems, bark, leaves, seeds, the fruit of the plant in water for a certain period so that the fibers are released, then the fibers are cleaned with clean water and dried. Table 1 below summarizes the process of extracting fiber from several types of grass fiber.

Table 1 Grass fibers extraction process

\begin{tabular}{llc}
\hline \multicolumn{1}{c}{ Fibers } & \multicolumn{1}{c}{ Extraction process } & Reference \\
\hline Mendong grass & $\begin{array}{l}\text { Water retting. Mendong straw was pounded } \\
\text { repeatedly and then cleaned using water. Then, fibers } \\
\text { were soaked in water for 7 days. Fibers were } \\
\text { retrieved, cleaned, and allowed to dry wind }\end{array}$ & {$[10]$} \\
& $\begin{array}{l}\text { Water retting. The fiber is soaked in water for 4 days, } \\
\text { then the fiber is separated manually, air-dried for } 8\end{array}$ & {$[14]$} \\
hours, oven 60 minutes at $160^{\circ} \mathrm{C}$. & \\
& $\begin{array}{l}\text { Water retting 28 days and dried at ambient } \\
\text { temperature for 7 days. }\end{array}$ & {$[18]$} \\
Kusha grass & $\begin{array}{l}\text { The mechanical process using decorticator } \\
\text { The mechanical process using decorticator }\end{array}$ & {$[22]$} \\
Sansevieria ehrenbergii & $\begin{array}{l}\text { Mechanical process decortication, the fiber washed } \\
\text { Sansevieria cylindrica }\end{array}$ & {$[21]$} \\
Elephant grass & $\begin{array}{l}\text { with water then dried in the sun for 24 hours } \\
\text { The culms of elephant grass were dried in shade for a }\end{array}$ & {$[13]$} \\
& &
\end{tabular}


Napier grass

Sansevieria trifasciata

Broom grass

Corn husks

Sisal

Belulang grass period of one week. They were soaked in water for a period of about 10 days.

Mechanical, grass stalks are ground with a roller, then water retting for 7 days, dried in the sun for 7 days

Water retting for 5 days and using the hand scrutching method, then washed with water and dried in the sun.

Water retting for 4 hours, extraction of fiber manually, then the fibers are dried 7 days, oven $70^{\circ} \mathrm{C}$ for 2 hours

Water retting, corn husks soaked in water for 16 days, extraction of fiber using a plastic comb, then the fibers are naturally air-dried

Water retting followed by scraping and mechanical using decorticators

Water retting 8 days, dried in at ambient condition for 24 hours. Separation of fibers by a mechanical process using a plastic comb
Present work

From table 1 above, the process of extracting grass fibers varies. Grass fiber extraction methods can be grouped into 3 parts: water retting process, mechanical process, the combination of mechanical processes with water retting. The most extraction process of grass fiber uses water retting because the process is very simple, easy to do, cheap and good result. Soaking time in the water retting process depends on the type of fiber, varying from 4 hours (Grass broom) to 28 days (Kusha grass). The average soaking time is 7 days. Some fibers can be separated during the water retting process, some other fibers must be air-dried at room temperature for several days. Drying process the separated fiber can be grouped into 3 ways: drying under the sun, natural air dried, and oven.

\section{CHEMICAL PROPERTIES}

Natural fibers in general consist of layers of lignin, hemicellulose, cellulose. The outermost layer of fiber generally consists of a layer of lignin, the inner layer of the hemicellulose and the innermost cellulose. Cellulose is the most important part of natural fiber because cellulose has good adhesion properties with a matrix in the composite's production process. Fibers that have a high percentage of cellulose tend to have good mechanical properties. Table 2 presents the contents of cellulose, hemicellulose, and lignin from natural fibers of grass type. Also displayed is the moisture content of each fiber. Table 2 showed that some fibers have not been tested to determine chemical properties, including broom grass, Sansevieria trifasciata, elephant grass, snake grass. This gives an opportunity to carry out further research. The cellulose content of grass fiber varies from the smallest 43.2 (Arundo donax L) and the greatest value is 80 (Sansevieria ehrenbergii).

The hemicellulose content varies from the smallest of 10 (sisal) to the highest of 33.7 (Corn husk). Lignin content varies from the smallest of 3.44 (Mendong grass) to the greatest value of 21.63 (Napier grass). The moisture of each fiber varies from 6.08 (Sansevieria cylindrica) to 11,961 (Corn husk) 
A Review on Natural Fibers: Extraction Process and Properties of Grass Fibers

Table 2 Chemical properties of grass fibers

\begin{tabular}{lccccc}
\hline \multicolumn{1}{c}{ Fibers } & Cellulose & Hemicellulose & Lignin & $\begin{array}{c}\text { Moisture } \\
\text { (wt \%) }\end{array}$ & References \\
\hline Mendong grass & 72.14 & 20.2 & 3.44 & - & {$[10]$} \\
Snake grass & - & - & - & - & {$[14]$} \\
Kusha grass & 70.58 & - & 14.35 & 8.01 & {$[18]$} \\
Arundo donax L & 43.2 & 20.5 & 17.2 & - & {$[22]$} \\
Sansevieria ehrengergii & 80 & 11.25 & 7.8 & 10.55 & {$[15]$} \\
Sansevieria cylindrica & 79.7 & 10.13 & 3.8 & 6.08 & {$[21]$} \\
Elephant grass & - & - & - & - & {$[13]$} \\
Napier grass & 47.12 & 31.27 & 21.63 & - & {$[12]$} \\
Sansevieria trifasciata & - & - & - & - & {$[23]$} \\
Broom grass & - & - & - & - & {$[17]$} \\
Corn husk & 46.15 & 33.7 & 3.92 & 11.961 & {$[24]$} \\
Sisal & 78 & 10 & 8 & 11 & {$[20]$} \\
Belulang grass & 45.8 & 32.29 & 7 & 11.36 & Present work \\
\hline
\end{tabular}

\section{PHYSICAL PROPERTIES}

Natural fiber has advantages compared to glass fiber, one of which is lighter density. Each fiber has a different density. The measurement of fiber density is measured in several ways. Some researchers use the Truong method [26] to determine the density of fibers. Fiber density is measured with a pycnometer using the Archimedes principle, where the volume of fiber dipped in a liquid is equal to the volume of spilled liquid.

$$
\rho_{\mathrm{f}}=\frac{(m 2-m 1) \rho l}{((m 3-m 1)-(m 4-m 2)}
$$

$\rho_{\mathrm{f}}$ is the density of the fiber, $\rho \mathrm{l}$ the density of the liquid in the pycnometer, $\mathrm{m}_{1}$ mass of the empty pycnometer, $\mathrm{m}_{2}$ of the pycnometer mass filled with fiber, $\mathrm{m}_{3}$ mass of the pycnometer filled with liquid, $\mathrm{m}_{4}$ mass of the pycnometer filled with liquid and fiber. Fiber density is used to determine the weight fraction and fiber volume fraction in composite production. Besides density, an important physical property is fiber diameter. Fiber diameter is needed to determine the tensile strength of single fiber for each grass fiber. The diameter of grass fibers varies greatly because of the irregular cross-section shape of the fibers. The diameter of the fiber is measured by microphotographs with micrometers $(\mu \mathrm{m})$.

Table 3 Physical properties of grass fibers

\begin{tabular}{lccc}
\hline \multicolumn{1}{c}{ Fibers } & Density $\left(\mathbf{g r} / \mathbf{c m}^{\mathbf{3}}\right)$ & Diameter $(\boldsymbol{\mu m})$ & References \\
\hline Mendong grass & 0.892 & $338 \pm 56$ & {$[10]$} \\
Snake grass & 0.887 & $45-250$ & {$[14]$} \\
Kusha grass & 1.1025 & $70-100$ & {$[18]$} \\
Arundo donax L & 1.168 & - & {$[22]$} \\
Sansevieria ehrengergii & 0.887 & $20-250$ & {$[15]$} \\
Sansevieria cylindrica & 0.915 & - & {$[21]$} \\
Elephant grass & 0.817 & $70-400$ & {$[13]$} \\
Napier grass & 0.358 & $150-550$ & {$[12]$} \\
Sansevieria trifasciata & 1.4147 & $80-120$ & {$[23]$} \\
Broom grass & 0.864 & $185-520$ & {$[17]$} \\
Corn husks & 0.34 & 0.186 & {$[24]$} \\
Sisal & 0.76 & $122-135$ & {$[20]$} \\
Belulang grass & 1.2138 & $81-178$ & Present work \\
\hline
\end{tabular}


Table 3 contains a comparison of the density and diameter of each grass fiber. From table 3 it is shown that the density of grass fiber is still smaller than the density of glass fiber, very suitable for light product applications. The smallest density of corn husk fiber is $0.34 \mathrm{gr} / \mathrm{cm}^{3}$ and the highest density of Sansevieria trifasciata is $1.4147 \mathrm{gr} / \mathrm{cm}^{3}$. There are $30 \%$ of fibers whose density is above $1 \mathrm{gr} / \mathrm{cm}^{3}$, one of which is belulang grass. The diameter of grass fiber also varies from the smallest namely corn husk of $0.186 \mu \mathrm{m}$ to the largest namely elephant grass of $400 \mu \mathrm{m}$. The fiber diameter value is very useful to determine the surface area and the tensile strength of a single fiber.

\section{MECHANICAL PROPERTIES}

The tensile test is one of the most widely used material tests. The tensile test is testing of test material by pulling the material until it breaks.

$$
\sigma=\frac{F}{A_{0}}
$$

$\sigma$ is the tensile strength (Mpa) value, $F$ is the force used to pull the fiber $(N), A_{o}$ is the cross-sectional area of the fiber $(\mathrm{mm} 2)$.

Table 4 Mechanical properties of grass fibers

\begin{tabular}{lcccc}
\hline \multicolumn{1}{c}{ Fibers } & $\begin{array}{c}\text { Tensile } \\
\text { Strength } \\
\text { (Mpa) }\end{array}$ & $\begin{array}{c}\text { Young's } \\
\text { modulus } \\
\text { [GPa] }\end{array}$ & $\begin{array}{c}\text { Elongation } \\
\text { at break } \\
(\%)\end{array}$ & References \\
\hline Mendong grass & $452 \pm 47$ & $17.4 \pm 3.9$ & - & {$[10]$} \\
Snake grass & 278.82 & 9.71 & 2.87 & {$[14]$} \\
Kusha grass & - & - & - & {$[18]$} \\
Arundo donax L & 248 & 9.4 & 3.24 & {$[22]$} \\
Sansevieria ehrenbergii & $50-585$ & $2.5-7.5$ & $2.8-21.7$ & {$[15]$} \\
Sansevieria cylindrica & 658 & 7.6 & 10 & {$[21]$} \\
Elephant grass & 185 & 7.4 & 2.5 & {$[13]$} \\
Napier grass & 88.4 & 13.15 & 0.99 & {$[11]$} \\
Sansevieria trifasciata & - & - & - & {$[23]$} \\
Broom grass & 297.58 & 18.28 & 2.87 & {$[17]$} \\
Corn husks & $160.49 \pm 17.2$ & $4.57 \pm 0.54$ & $21.08 \pm 2.86$ & {$[24]$} \\
Sisal & $536-640$ & $9.4-22$ & $3-7$ & {$[20]$} \\
Belulang grass & $116.5-445.1$ & $0.97-3.68$ & $0.98-1.7$ & Present work \\
\hline
\end{tabular}

The purpose of this tensile test is to determine the tensile strength of the material. The higher the tensile strength value of a material, the stronger the material, and vice versa. The value of the mechanical properties of grass fiber can be seen in table 4 .

From table 4 above, Kusha grass and Sansevieria trifasciata need research to determine its mechanical properties. The tensile strength value of grass fiber varies from $88.4 \mathrm{MPa}$ (Napier grass) to $640 \mathrm{MPa}$ (Sisal). Young's modulus also varies from $0.97 \mathrm{GPa}$ (Belulang grass) to $18.28 \mathrm{Gpa}$ (Broom grass). Elongation at break also varies from $0.98 \%$ (Belulang grass) to $21.08 \%$ (Corn husks). Mechanical strength is a combination of the value of tensile strength, the value of young modulus, and the value of elongation at break. The value of mechanical strength of materials used by designers to design a product in the industry

\section{CONCLUSION}

EXTRACTION Process, classified into three types, water retting, mechanical process, and a combination of mechanical process and water retting. The soaking time in the water retting 
process varies from 4 hours to 28 days. Drying the separated fiber by three ways: drying under the sun, natural air dried, and oven.

Chemical Properties, the cellulose content of grass fiber varies from the smallest 43.2 (Arundo donax L) and the greatest value is 80 (Sansevieria ehrengergii). The cellulose content varies from the smallest of 10 (Sisal) to the highest of 33.7 (Corn husks). Lignin content varies from the smallest of 3.44 (Mendong grass) to the greatest value of 21.63 (Napier grass). Moisture of each fiber varies from 6.08 (Sansevieria cylindrica) to 11,961 (corn husks)

Physical Properties, the density of grass fiber is still smaller than the density of glass fiber, very suitable for light product applications. the smallest density of corn husk fiber is 0.34 $\mathrm{gr} / \mathrm{cm}^{3}$ and the highest density of Sansevieria trifasciata is $1.4147 \mathrm{gr} / \mathrm{cm}^{3}$. there are $30 \%$ fibers whose density is above $1 \mathrm{gr} / \mathrm{cm}^{3}$, one of which is belulang grass. the diameter of grass fiber also varies from the smallest namely corn husks of $0.186 \mu \mathrm{m}$ to the largest namely elephant grass of $400 \mu \mathrm{m}$. the fiber diameter value is very useful to determine the surface area and the tensile strength of a single fibers.

Mechanical Properties, the tensile strength value of grass fiber varies from $88.4 \mathrm{MPa}$ (Napier grass) to $640 \mathrm{MPa}$ (Sisal). Young's modulus also varies from $0.97 \mathrm{GPa}$ (Belulang grass) to $18.28 \mathrm{Gpa}$ (Broom grass). Elongation at break also varies from 0.98\% (Belulang grass) to $21.08 \%$ (Corn husks). Mechanical strength is a combination of the value of tensile strength, the value of young modulus, and the value of elongation at break. The value of mechanical strength of materials used by designers to design a product in the industry

\section{ACKNOWLEDGMENT}

Thanks to Prof. NPG Suardana, Prof. I Wayan Surata, Prof. I Nyoman Suprapta Winaya, who guided this research

\section{REFERENCES}

[1] Jawaid, M., and Abdul Khalil, H. P. S, Cellulosic/synthetic fiber reinforced polymer hybrid composites: A review. Carbohydrate Polymer. 86, 2011, pp. 1-18.

[2] Satyanarayana, K. G, Guimaraes. J. L and Wypych. F, Studies on lingo cellulosic fibers of Brazil. Part I: Source, production, morphology, properties, and applications, Composites Part A, 38, 2007, pp. 1694-1709.

[3] Malkapuram, R., Kumar. V and Yuvraj. S. N, Recent development in natural fibre reinforced polypropylene composites, Journal Reinf. Plast. Compos. 28, 2009, pp. 11691189.

[4] L. Sanchez Nacher, J. E. Crespo Amoros, M. D. Salvador Moya and J. Lopez Martinez, Mechanical properties of polyester resins in saline water environments, Int. J. Polym. Anal. Charact. 12(5), 2007, pp. 373-390.

[5] Thakur. V. K, Singha. S.A and Mehta. I.K, Renewable resource-based green polymer composites: Analysis and characterization, Int. J. Polym. Anal. Charact. 15, 2010, pp. 137-148.

[6] M.R.Ishak, Z.Leman, S.M. Sapuan A, M. M. Edeerozey and I. S. Othman, and Nmegbu, Mechanical Properties of kenaf bast and core fiber reinforced unsaturated polyester composites, IOP Conf. Series: Materials Science and Engineering, 11, 2010, pp. 1-6, 2010

[7] Mayandi. K, Rajini. N, Pitchipoo. P, Winowlin Jappes. J. T and Varada Rajulu. A I.A.A.C., Extraction, and characterization of new natural lingo cellulosic fiber Cyperus pangorei. Int.J. Polym. Anal. Charact, 21, 2016, pp. 175-183. 
[8] Mahato, D. N, Prasad, R.N and Mathur. B.K, Surface Morphological, band, and lattice structural studies of cellulosic fiber coir under mercerization by ESCA, IR and XRD techniques, Indian Journal of Pure \& Applied Physics, 47, 2009, pp. 643-647.

[9] Hassan, M. M., Islam. M.R, and Khan. M.A, Influence of additives on the performance of photographed jute yarn with 3- (trimethoxysilyl) propyl methacrylate, Int. J. Polym. Anal. Charact, 10(3), 2005, pp. 179-194.

[10] Heru Suryanto, Eko Marsyahyo, Yudy Surya Irawan \& Rudy Soenoko, Morphology, Structure, and Mechanical Properties of Natural Cellulose Fiber from Mendong Grass (Fimbristylis globulosa), Journal of Natural Fibers, 11(4), 2014, pp.333-345.

[11] Haameem J.A, M., M. S. Abdul Majid, M. Afendi, H. F. A. Marzuki, I. Fahmi, and A. G. Gibson. Mechanical Properties of Napier Grass Fibre/Polyester Composites, Composite Structures, 136 (2), 2016, pp. 1-10.

[12] Kommula, V.P., Reddy, K.O., Shukla, M., Marwala, T., Reddy, E.V.S., Rajulu, A.V. 2016. Extraction, modification, and characterization of natural lignocellulosic fiber strands from Napier grass. International Journal of Polymer Analysis and Characterization, 21(1), 2016, pp.18-28

[13] Rao, K. Murali Mohan, A. V. Ratna Prasad, M. N. V. Ranga Babu, K. Mohan Rao, and A. V. S. S. K. S. Gupta. Tensile Properties of Elephant Grass Fiber Reinforced Polyester Composites, Journal of Materials Science, 42 (9), 2007, pp. 3266-72.

[14] Sathishkumar, T, P. Navaneethakrishnan, S. Shankar, and R. Rajasekar. Mechanical Properties and Water Absorption of Short Snake Grass Fiber Reinforced Isophthalic Polyester Composites, Fibers and Polymers, 15 (9), 2014, pp. 1927-34.

[15] Sathishkumar, T.P., Navaneethakrishnan, P., Shankar, S., and Rajasekar, R. Characterization of new cellulose sansevieria ehrenbergii fibers for polymer composites. Composite Interfaces, 20(8), 2013, pp. 575-593.

[16] A. V. Ratna Prasad, K. Mohana Rao, A. V. S. S. K. S. Gupta, B. V. Reddy, A Study On flexural Properties Of Wildcane Grass fiber-Reinforced Polyester Composites, J Mater Sci, 46, 2011, pp. 2627-2634.

[17] Ramanaiah, K., Ratna Prasad, A.V., dan Hema Chandra Reddy, K., Thermal And Mechanical Properties Of Waste Grass Broom Fiber-Reinforced Polyester Composites. Materials \& Design, 40, 2012, pp. 103-108.

[18] A. N. Balaji, M. K. V. Karthikeyan \& V. Vignesh, Characterization of New Natural Cellulosic Fiber From Kusha Grass, Int. J.Polym. Anal. Charact, 21, 2016, pp. 29-39.

[19] Ibrahim, I.D., Jamiru, T., Sadiku, R.E., Kupolati, W.K., dan Agwuncha, S.C., Dependency of the Mechanical Properties of Sisal Fiber Reinforced Recycled Polypropylene Composites on Fiber Surface Treatment, Fiber Content, and Nanoclay, J Polym Enviro, 2016.

[20] Li Y, Mai Y-W, and Ye L. Sisal fiber and its composites: a review of recent developments. Compos Sci Technol, 60, 2000, pp.2037-2055.

[21] Sreenivasan, V.S., Somasundaram, S., Ravindran, D., Manikandan, V., dan Narayanasamy, R. Microstructural, Physico-chemical and mechanical characterization of Sansevieria cylindrica fibers - An exploratory investigation. Materials \& Design, 32(1) 2011, pp.453-461

[22] V. Fiore, T.Scalici, A. Valenza, Characterization of a New Natural Fiber From Arundo donax L. as Potential Reinforcement of Polymer Composites, Carbohydrate Polymers, 106, 2014, pp. 77-83. 
[23] Samson Rwawiire \& Blanka Tomkova, Morphological, Thermal, and Mechanical Characterization of Sansevieria trifasciata Fibers, Journal of Natural Fibers, 12(3), 2015, pp.201-210.

[24] Nasmi Herlina Sari, I.N.G. Wardana, Yudy Surya Irawan \& Eko Siswanto, Characterization of the Chemical, Physical, and Mechanical Properties of NaOH-treated Natural Cellulosic Fibers from Corn Husks, Journal of Natural Fibers, 15(4), 2017, pp. 545-558

[25] Munawar SS, Umemura K and Kawai S. Characterization of the morphological, physical, and mechanical properties of seven nonwood plant fiber bundles. J Wood Sci, 53, 2007, pp.108-113

[26] Truong, M., Zhong, W., Boyko, S., Alcock, M., A comparative study on natural fibre density measurement. The Journal of The Textile Institute 100(6), 2009, pp. 525-529. 